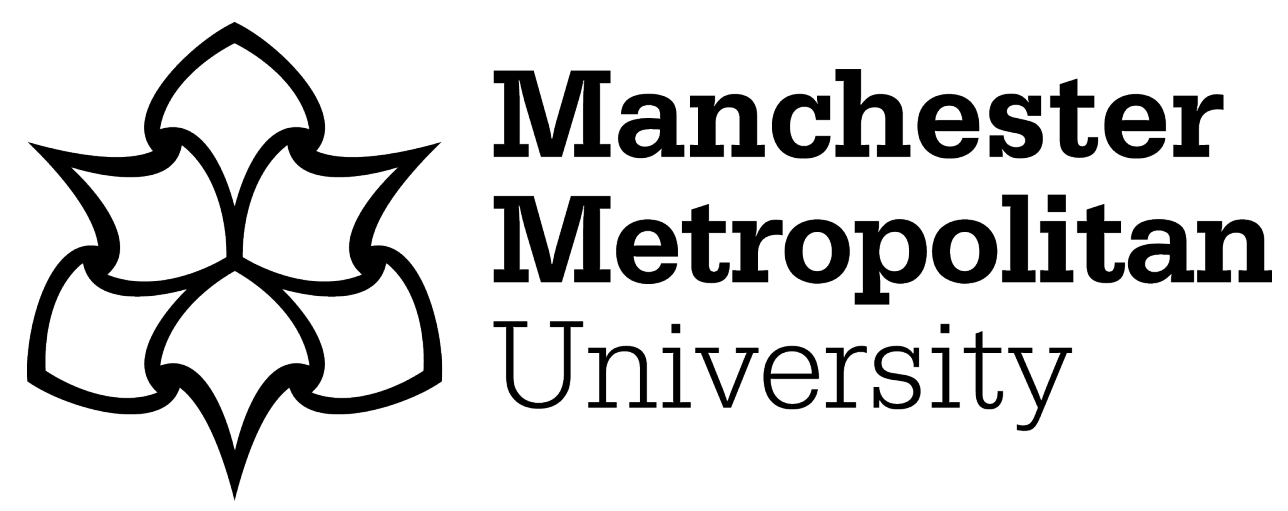

McNicol, Sarah ORCID logoORCID: https://orcid.org/0000-0001-8196-6680, Lewin, Cathy ORCID logoORCID: https://orcid.org/0000-0002-3430-4075, Keune, Anna and Toikkanen, Tarmo (2014) Facilitating student reflection through digital technologies in the iTEC project: Pedagogically-led change in the classroom. In: First International Conference, LCT 2014 (held as part of $\mathrm{HCl}$ International 2014), 22 June 2014 - 27 June 2014, Heraklion, Crete, Greece.

Downloaded from: https: //e-space.mmu.ac.uk/323368/

Version: Accepted Version

Publisher: Springer

DOI: https://doi.org/10.1007/978-3-319-07485-6_30

Please cite the published version 


\title{
Facilitating student reflection through digital technologies in the iTEC project: pedagogically-led change in the classroom
}

\author{
Sarah McNicol ${ }^{1}$, Cathy Lewin ${ }^{1}$, Anna Keune $^{2}$ and Tarmo Toikkanen ${ }^{2}$ \\ ${ }^{1}$ Education and Social Research Institute, Manchester Metropolitan University, 799 Wilmslow Road, Didsbury, \\ Manchester M20 2RR, UK \\ ${ }^{2}$ Learning Environments Research Group, Aalto University, PL 11000, 00076 Aalto, Finland
}

\begin{abstract}
During the Europe-wide iTEC project, student reflection has been supported through the development of two dedicated digital tools: TeamUp and ReFlex. Using these tools, students are able to monitor their progress, thus gaining a greater awareness of their learning achievements and an appreciation of the new skills they have developed. Although TeamUp and ReFlex have been well-received by teachers and students, the use of audio-visual tools to support reflection was novel for most and the project evaluation highlighted the need for detailed guidance if these technologies are to be exploited to their full advantage.
\end{abstract}

Keywords: Reflection; audio-visual tools; scaffolding; digital tools

\section{Introduction}

iTEC $^{1}$ is a four year European Commission-funded project which aims to transform the way that existing and emerging technologies are used in teaching and learning throughout European schools. Within iTEC, teachers are encouraged to adopt reflection as a key learning activity, to support independent learning and critical thinking and increase students' confidence, self-awareness and motivation. Although a wide variety of methods and tools can be used to support reflection, from diaries and logbooks to wikis, blogs, and video diaries, in iTEC, the emphasis has been on using audio-visual tools. In particular, student reflection has been supported through the development of two dedicated digital tools: TeamUp and ReFlex, as well as the use of existing audio-visual reflection tools such as VoiceThread ${ }^{2}$, a cloud application which allows the upload and sharing of over fifty types of media and commentary using microphone, webcam, text, phone or audio-file upload.

\section{Supporting reflection}

Reflection can be defined as a process that allows the learner to "integrate the understanding gained into one's experience in order to enable better choices or actions in the future as well as enhance one's overall effectiveness" [1]. The benefits of reflection as a vital component of the learning process are well rehearsed; as Hinett comments, "The benefits of reflection and associated techniques such as self- and peer-assessment speak for themselves. Students develop interpersonal skills, improve confidence and sustain motivation for their studies by monitoring and taking responsibility for their own development" [2]. Fuher argues that students are often better able to recognise their thoughts simply by documenting them [3], while more challenging forms of reflection push students to think in new ways and develop alternative explanations for experiences and observations, as demonstrated by Eyler and Giles [4]. The act of reflection therefore promotes independent learning and critical thinking as we "make sense of what we've learned, why we learned it, and how that particular increment of learning took place" [5]. Through reflection, students also learn to organise and express their thoughts, increasing confidence and selfawareness. As they become more aware of their progress, motivation can increase.

As Rogers points out, however, reflection remains a challenging concept for educators to apply in practice in spite of the potential for positive outcomes [1]. For example, research involving higher and continuing education students found that many do not initially understand how reflection may help them and feel that reflection is over-emphasised, failing to see its relevance to their learning $[6,7]$. Moreover, there is limited evidence of adoption of reflection in primary and secondary school contexts [8]. This is particularly true in relation to 'live reflection' [9], or as Schön termed it, 'reflection-in-action' [10], that is, reflection conducted during the learning processes rather than after the events. Yet evidence suggests that supporting student metacognition and self-regulated learning can lead to 7-9 months additional progress [11]. Therefore, there is a need to identify how to support teachers engaging with student reflection as part of their pedagogical repertoire.

From Dewey [12] onwards, various models have been developed to describe and support, or scaffold, the reflection process and many follow a similar format, with an initial descriptive stage, followed by a more critical evaluation, which is then used as the basis for determining future actions. For example, the Driscoll Cycle (or 'What? So What? Now What?' framework), which can be mapped onto Kolb's Experiential Learning Cycle, starts with a description of the event, followed by an analysis of the event, which is then used to determine future actions [13]. Prompt questions are a common means of helping students to reflect and to make sense of their learning. An example is articulated learning (AL), as described by Ash and Clayton, which is structured in accordance with four guiding questions:

1) What did I learn?

\footnotetext{
${ }^{1} \mathrm{http}: / /$ itec.eun.org

2 http://voicethread.com/
} 
2) How, specifically, did I learn it?

3) Why does this learning matter, or why is it significant?

4) In what ways will I use this learning?

They found, however, that students need more than just the four questions structuring the AL to achieve deep, critical learning [14].

Alongside these process frameworks, models have also been developed to classify students' reflective activities. For instance, Kember et al devised a series of coding categories for reflective thinking, which range from 'habitual action' to 'premise reflection", the latter suggesting a, "significant change of perspective" [15].

\section{Reflection and technology}

Lin et al identify four ways in which theoretical frameworks suggest that technology can provide powerful scaffolding for reflection, namely, process displays (displaying problem-solving and thinking processes); process prompts (prompting students' attention to specific aspects of processes while learning is in action); process models (modelling of experts' thinking processes so that students can compare and contrast with their own process in action); and forums for reflective social discourse (creating community-based discourse to provide multiple perspectives and feedback that can be used for reflection). They argue that technology can often ensure that scaffolds to enhance reflection to occur in ways that are difficult to achieve in more traditional learning environments, for example, through guided prompts at critical points. They also describe the "leverage provided by technology to display learning processes in multiple formats, such as graphics, text, animation or audio" [16].

In a practical context, it has been demonstrated that technology can be used effectively to support reflection [17]. Audiovisual formats (eg video, multimedia web applications) are increasingly being used as an effective medium for reflection, particularly for pre-service and practicing teachers $[18,19,20]$. More recently, Voicethread has been used to student reflection in a higher education context [21,22]. However, the use of audio-visual formats to support reflection is not always effective [17]. For instance, in a case study comparing written and multimedia reflection methods, Holland and Purnell found no evidence that using technology enhanced students' level of reflection and it may actually have hindered the reflective process as narratives were read from a prepared script. Furthermore, staff judged that all the multimedia reflections contained less reflection than written work [23]. In school contexts in particular, whilst potential for the use of blogs and e-portfolios to support reflection in school contexts has been noted $[9,24]$, there is little evidence of innovative uses of technology to support formative assessment and reflection in primary and secondary schools [25].

\section{iTEC: Innovative Technologies for Engaging Classrooms}

The iTEC school pilots are being delivered over four years (2010-14) in five overlapping 18-month cycles involving both primary and secondary schools. The number of European countries involved varies between cycles, as does the number of teachers (each of whom runs pilots with 1 to 3 cohorts, or classes, of learners). During the four cycles which have been completed to date, 278 cohorts from 17 countries participated in Cycle 1; 421 cohorts from 15 countries in Cycle 2; 407 cohorts from 18 countries in Cycle 3 and 874 cohorts from 19 countries in Cycle 4. A team from the Education and Social Research Institute (ESRI) at Manchester Metropolitan University (MMU) in the UK is responsible for the evaluation of iTEC. Each country has a national co-ordinator who oversees the project and supports teachers.

At the end of each cycle, teachers who have participated complete an online questionnaire about their experiences, focusing on their use of the iTEC technologies, including reflective tools, as well as more general benefits, enabling factors, challenges encountered and potential for innovation. National co-ordinators conduct one or more case studies in their country each cycle, involving lesson observation and interviews with teachers, headteachers, ICT co-ordinators and students. These are returned to the evaluation team as case study reports (cycles 1-3 only, two per cycle) or transcripts (all cycles, one per cycle). In cycle 4, national co-ordinators also conducted a focus group with a sample of teachers from their country. In addition, members of the evaluation team have gathered data through the observation of project activities such as training sessions and webinars. The focus of the evaluation has altered slightly during each cycle to adapt to the needs of the project, so the precise questions asked within the survey and interviews have changed, meaning direct comparison between cycles is not possible for all measures.

Qualitative data are analysed using Nvivo. Transcriptions and notes are initially coded thematically using a conceptual framework from the SITES2 study [26], but an iterative approach is adopted with the initial framework being modified to incorporate new codes to reflect emerging themes. The survey comprises both open-ended and closed questions; the openended questions are translated into English using Google Translate and then analysed using Excel, while the closed questions are analysed using SPSS.

\section{Audio-visual reflection tools in iTEC}


The two prototype audio-visual reflection tools created as part of iTEC, TeamUp ${ }^{3}$ and ReFlex ${ }^{4}$, are open source tools, which will continue to be available beyond the project and are free to use and adapt. TeamUp (Fig. 1) has been used throughout the project $^{5}$. This prototype tool allows teachers to create teams of students based on shared interests and/or other criteria such as gender. It also offers the facility for groups of students to record 60-second audio 'newsflashes' in the style of news bulletins which are stored with an image of themselves or work they are engaged in at the time of recording. When recording the 'newsflash' students are prompted on screen to respond to three points (highlighted at 20 second intervals): what they have done, what they will do next, and any problems encountered. This enables the group to reflect on their progress in group projects or learning activities, as well as achievements and future needs of work in progress. The audio-visual reflection recordings of a group are available to other students and their teacher. Anyone with access to the classroom space may listen to the recording of any group and create recordings for any group. For example, the teacher can use the reflections to monitor progress and inform assessment. Although focus lies on creating reflections of work in progress throughout project, teachers are advised to ask students to record a final reflection at the end of the project summarising activities, explaining how problems were overcome, and outlining next steps.

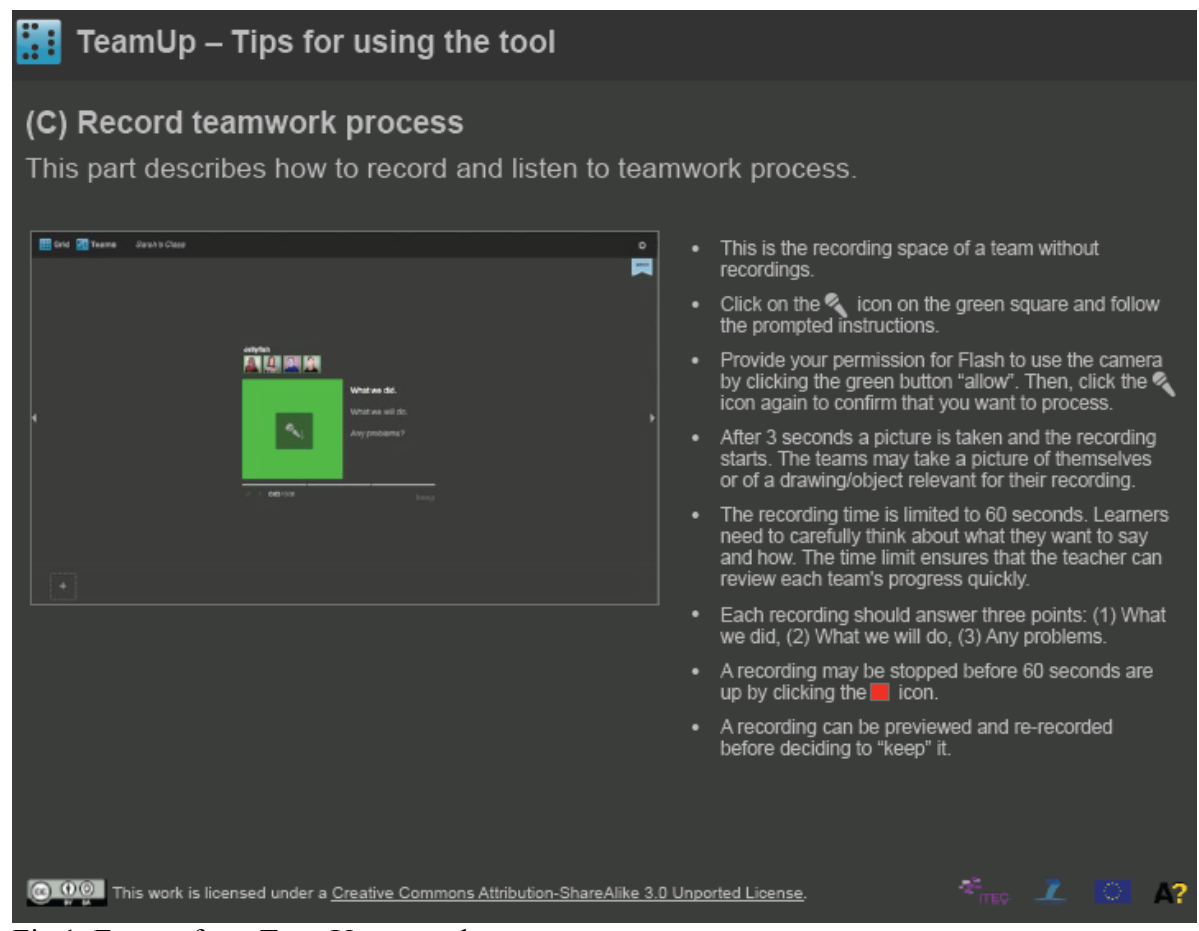

Fig 1. Extract from TeamUp manual

ReFlex (Fig 2) is a more recently developed prototype; it enables students to build up a series of 60-second audio-clip reflections about their learning which are subsequently displayed on a timeline. Students can use ReFlex as a learning diary which also helps the teacher to monitor students' activities; it is intended to be used to facilitate one-to-one guidance sessions between the teacher and the student. A student's recordings are only available to themselves and their teacher. ReFlex also has a 'time capsule' feature, where the student can record a 'note' and send it to the future as a milestone or learning goal.

\footnotetext{
${ }^{3} \mathrm{https} / / /$ sites.google.com/site/itectectester/services/teamup

${ }^{4} \mathrm{https} / / /$ sites.google.com/site/itectectester/services/reflex

${ }^{5}$ Although in Cycle 1 data was not collected on the use of TeamUp as a reflection tools specifically.
} 


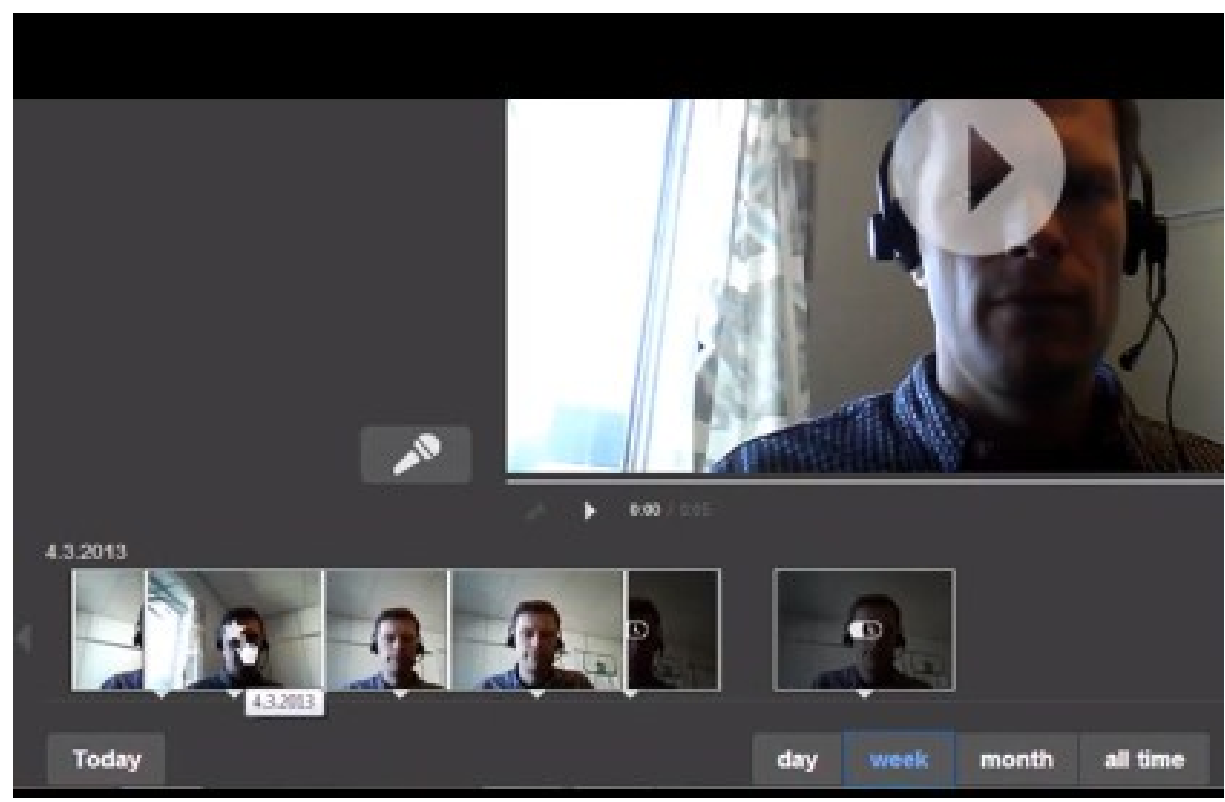

Fig 2. Screenshot of ReFlex 'reflection space'

The reflection tools used within the iTEC project can therefore be said to focus on the 'process display' [16] feature of scaffolding as students used the tools to make their problem-solving and thinking processes more visible and later review these as a means of reflecting on progress. In addition, it could be argued that TeamUp includes a simple implementation of 'process prompts' [16].

Teachers participating in the project have been implementing packages of learning activities ${ }^{6}$ in their classrooms, in many cases within a 'learning story', or narrative exemplifying how a package of learning activities may support learning and teaching in the classroom. This has usually been in the form of a 'project' taking place over several lessons. In each cycle to date, teachers have been presented with the packages of learning activities and two to three learning stories, all designed to inspire teachers to do things differently and make more use of technology in their pedagogical practices. For example, during the last project cycle the learning activities have suggested a design-based learning process, in which students are asked to develop ideas and to question a design-brief, explore the context of their ideas through methods, such as mapping and stakeholder interviews, and to iteratively develop an artefact. These resources are not intended to be prescriptive and as a result each individual implementation can be unique as teachers adapt them to meet their needs and to fit with the technology infrastructures in their schools. Each package of learning activities has included one dedicated to reflection, focussing on project progress, perceived challenges and future plans. Teachers were asked to decide how many times their students would record reflections, with a recommendation that it should take place at the end of each day of project activity.

To date, Reflex has only been used by a small number of teachers (27 of those participating in Cycle 4). TeamUp has been more widely trialled however. During the second cycle of the project, TeamUp was used to record reflections with $30 \%$ of cohorts whilst an alternative tool was used in $33 \%$ of cohorts $(n=262)$. The corresponding figures for Cycle 3 were $28 \%$ and $21 \%(\mathrm{n}=334)$. In $\mathrm{C} 4,30 \%$ of cohorts $^{7}$ used TeamUp to record student reflections $(\mathrm{n}=424)$. During Cycles 2 and 3 , teachers listened to the recordings made by $85 \%$ of cohorts using TeamUp and around three-quarters $(74 \%$ and $77 \%)$ asked their students to listen to the recordings. In Cycle $2^{8}$, the majority of students were asked to record reflections 1-5 times.

\section{The benefits of reflection using audio-visual tools}

The evaluation has found that reflection using iTEC digital tools has enabled both students and teachers to monitor the progress of their work by giving them a greater awareness of the progress they were making:

Students and the teacher reviewed their recordings next time. It was easy to follow projects' progression. (Finland, teacher, C3)

Students in a class in Israel discussed how, initially, they viewed the time they spent reflecting as time wasted; some felt frustrated because they felt this meant less time for what they considered to be learning. However, after using TeamUp for

\footnotetext{
${ }^{6} \mathrm{http}: / /$ itec.aalto.fi/learning-stories-and-activities/

${ }^{7}$ Data on number of cohorts was not provided in all cases in Cycle 4; this figure is calculated on the assumption that those teachers for whom no data is available ran the activities with one cohort.

${ }^{8}$ This question was not asked in other cycles.
} 
several weeks, their opinions changed and they began to see its value as a project management tool. They came to realise TeamUp was, "not only as a technical tool but also as a way of learning" (Israel, student, C4) as it enabled them to appreciate the learning process and to consider each stage, rather than only focusing on the final outputs:

Team Up really helped us in planning - think about what we did and what they are going to do at the next meeting. It made me think about the process and not just on the object [learning output]." (Israel, student, C4).

Using the iTEC tools, students were also able to reflect more generally on their learning development and to identify new skills they had acquired. Teachers commented that recording reflections helped to develop students' skills in self-evaluation; as they became "more aware of the learning process" (Spain, teacher, C4) and they were able to see how they were developing as individuals:

It forces students to think about their work, become aware of the work we have been able to do, and skills they have developed. (Spain, teacher, C3)

This realisation could be motivational for students as it made them aware of the progress they had made and encouraged them to undertake further work:

It also stimulates you to work, because you know that if you do so you will have a lot to record and you can listen to the progress you have made. (Israel, student, C4)

As well as reflecting on their progress and development as individuals, students engaged in peer-to-peer learning as they shared their individual reflections with each other. Students believed that the iTEC tools supported them in reflecting on their work as a group, not just as individuals and also helped them to "connect to the group" (Israel, student, C4).

Students felt that documenting their reflection in some way was crucial and using technology to support reflection had notable advantages over traditional methods such as written journals. Although students commented that the process was more important than the tool itself, they believed that the act of recording (and listening back to) their reflection made them think more critically about their comments and encouraged them to construct their statements more clearly than they might do in a written document :

If you write it on a page, maybe you invest less time on the phrasing. But if you must also speak and hear yourself talk, then you must express it correctly.[...] You hear just what you say, and what intonation, so it requires you to speak more to the point, concisely and clearly. (Israel, students, C4)

Using digital tools to support reflection also had benefits for teachers. It enabled them to monitor individual and group progress more effectively and learn from students' reflections, using these to better appreciate where students were struggling and to identify where they needed to make changes to their pedagogical approach or provide additional support.

What I really liked was the various types of feedback. What we did today, and what the kids summarized, namely what they liked and what they disliked, why it was different [...] I learnt things about the kids that I would not have known otherwise (Hungary, teacher, C4).

\section{Challenges of using audio-visual tools for reflection}

There were a number of challenges experienced in using audio-visual tools for reflection however. This was not unexpected as the use of digital tools to support reflection was clearly new for both students and teachers:

Some tasks, such as reflection or showing the work produced by students, were carried out using ICT. Normally I do not use ICT for the accomplishment of these tasks. (Portugal, teacher, C4)

As TeamUp and Reflex were new tools which neither teachers nor students had used before, it took some time for both groups to become familiar with them. To help students learn how to use the tools, a teacher in Israel tutored one student from each group, who was then responsible for supporting the other group members in their use of TeamUp.

Both tools were being refined and developed over the course of the project, so using prototype technologies meant that technical problems, such as a lack of infrastructure, equipment or support, could be a challenge:

...there were some connection problems and some problems with the use of Flash for video recording on some computers (Spain, teacher, C3). 
Furthermore, although using digital tools to support reflection was appealing to some students, others were less comfortable being asked to record their reflections:

\section{Recording was just embarrassing, some couldn't even record their voice (Portugal, teacher, C4)}

Other challenges identified did not merely relate to audio-visual methods of reflection, but to the activity of reflection more generally. Time was a common barrier to reflection. As well as the problems of technical bugs and unfamiliarity, as described above, this was partly due to the fact that reflection was often seen a supplementary activity, rather than an integral part of the learning process.

Another frequently mentioned problem was students' lack of evaluation skills; case study teachers often felt that students tended to simply describe the process they had undertaken rather than reflecting on the successes and challenges experienced and the significance for their learning development. As reflection was something students were not used to doing many, and especially younger students, found it difficult to express their thoughts. As teachers explained:

It is not always easy to look at our own work from 'outside', the children often find it difficult to formulate their ideas (Hungary, teacher, C4)

...they [students] hardly made reflections, they simply told [the story of] what they made. Reflection as a method is very popular, but it is not easy for primary students to evaluate their own work. (Lithuania, teacher, C4)

Student attitudes could also present a challenge. Some students did not understand the value of reflection, regardless of the method used, and were therefore reluctant to take part in this learning activity. For example, a teacher referred to the problem of, "convincing students of the usefulness of this type of work" (Portugal, teacher, C4).

\section{Discussion}

As evidence from the evaluation of iTEC demonstrates, audio-visual tools can be used to support student reflection and offer a number of potential benefits, including being motivational for students; supporting project planning; and facilitating peerto-peer learning and group work in general. While the technical challenges of using audio-visual reflection tools are not too challenging to overcome with adequate support, and are likely to diminish over time, pedagogical and organisational issues are likely to present more persistent barriers. Perhaps the greatest challenge is that reflection, in any format, is not yet considered an integral aspect of the learning and teaching process in many European schools, hence the perceived lack of time for reflection; poor understanding of its relevance; and paucity of student skills reported in the iTEC evaluation. As Stephens and Winterbottom suggest, routine, structured reflection methods are less commonly used in schools compared to higher education [8].

Critically, as Boud and Walker point out, "reflection is not solely a cognitive process: emotions are central to all learning" [27]. The iTEC evaluation found student attitudes to be critical; if students did not appreciate the value of reflection, or were uncomfortable using audio-visual approaches, this proved to be a significant barrier. Teacher attitudes are equally important. Lin et al describe how, regardless of the medium used for reflection, the role of the teacher is crucial: "Providing students with tools for reflection does not guarantee that they will use them appropriately, if at all. Teachers are crucial in creating classroom norms and structures that increase the value that students place on reflection" [16].

Even if both teachers and students appreciate the value of reflection however, as Welch points out, it is not enough to tell students to "go and reflect"; rather, some form of scaffolding is necessary to help students to structure the way in which they reflect on their learning and to make sense of their experiences [28]. The guidance provided to support the use of TeamUp initially focused on three questions: 'What we did?' 'What we're going to do?' and 'Any problems?', echoing the tripartite reflection structure of the Driscoll Cycle [13] and similar models. From Cycle 3 onwards, this guidance was expanded to include two additional prompt questions: 'Did you overcome the challenges? (How?)'; and 'What challenges can you foresee? ${ }^{\prime 9}$. However, the evaluation findings suggest that students, and their teachers, required still more detailed guidance and support to make effective use of the TeamUp tool. This need for a more detailed structure is unsurprising given similar findings reported elsewhere [14]. Although iTEC students were generally able to master the first component of reflection: describing an experience, they found analysing this and reflecting on it to determine future actions to be more challenging. Students clearly needed more support in these specific aspects of reflection.

As Holland and Purnell reported, although digital tools may have potential to enhance reflection activities, there is a danger that, in practice, they may in fact detract from critical reflection, especially if audio-visual tools are seen merely as an

\footnotetext{
${ }^{9}$ http://itec.eun.org/c/document_library/get_file?uuid=665ee1c5-aae2-475b-a94c-724cb44931e7\&groupId=10136
} 
extension of written formats whereby students prepare and record a script [23]. Analysis of the evaluation data from iTEC offers a number of suggestions as to the ways in which teachers and students may make more effective use of digital tools to support reflection, capitalising on the inherent strengths of this format, rather than simply regarding it as a direct replacement for a written reflective journal. Some possible methods of enhancing the use of audio-visual reflection tools are described below. These are organised according to the four ways in which technology can provide powerful scaffolding for reflection identified by Lin et al [16]. Although it has not been possible to explore all of these within the timeframe of the project, they suggest ways in which iTEC resources, and similar audio-visual tools, could be further exploited in the future.

\section{Process display}

Developing 'newsflashes: One of the potential strengths of the TeamUp tool is the use of the idea of a 'newsflash' which will be familiar to students from television news bulletins. This concept might be further developed, for example, by students devising a headline which sums up their experiences in a few words, along with the use of images illustrating their 'reflection story'.

\section{Process prompts}

Interview structure: Lin et al discuss the use of process prompts embedded in digital tools to scaffold reflection [16], but another approach may simply be for one student to interview another, thereby providing the prompts for their reflection, and then reversing roles. Students can be assisted in devising their own prompts, or these can be provided by the teacher. The interview can be recorded and revisited by the student.

Thinking Hats: A widget based on de Bono's Thinking Hats ${ }^{10}$ has been used to support reflection by a number of iTEC teachers. Feedback indicates that students found this approach helpful as a means of looking at their project from different perspectives in order to analyse their learning experiences. This suggests that integrating this widget with the audio-visual reflection tools used may help in scaffolding.

\section{Process models}

Peer tutors: Peer tutors can help to overcome basic technical challenges and a lack of relevant ICT skills. These students can be trained by the teacher in the use of the digital reflection tools and then recognised as 'experts' who are able to support other members of their group in using the technologies.

\section{Reflective social discourse}

Paired reflection: Paired reflection may help to reduce the embarrassment students may experience when recording themselves and making reflections orally. Two students discussing their progress and reflecting in this way can be a more natural, and less pressured, setting than a single student speaking aloud to a camera.

Imaginative and creative approaches: Audio-visual tools might also be used to support more creative and imaginative approaches to reflection, such as the use of metaphors, poems or sketches to both describe and analyse learning.

\section{Conclusion}

The use of digital tools to support reflection was novel for most iTEC teachers and students and, although such tools were well-received, the evaluation highlighted the fact that detailed guidance needs to be provided if these technologies are to be exploited to their full advantage.

\section{Acknowledgements}

TeamUp, ReFlex and the iTEC Learning Activities were developed by the Learning Environments Research Group at Aalto University, Finland (http://legroup.aalto.fi). Thanks to all the teachers and students involved in the iTEC evaluation and to the national co-ordinators and their colleagues involved in data collection. Thanks also to Maureen Haldane, iTEC work package 5 co-lead investigator during Cycles 1-3. iTEC is coordinated by European Schoolnet (EUN) and co-funded by the European Commission's 7th Framework Programme.

\section{References}

1. Rogers, R.: Reflection in Higher Education: A concept analysis. Innovative Higher Education 26, 37-57 (2001).

2. Hinnet, K.: Improving Learning Through Reflection - Part One, http://www.heacademy.ac.uk/assets/documents/resources/database/id485_improving_learning_part_one.pdf (2002).

3. Fuher, C.: Response Journals: just one more time with feeling. Journal of Reading 37(5), 400-405 (1994).

4. Eyler, J., Giles, D. E.: Where's the Learning in Service-learning? Jossey-Bass, San Francisco, CA (1999).

\footnotetext{
${ }^{10} \mathrm{http}: / /$ exchange.smarttech.com/details.html?id=c22fce6f-b61f-4bf2-a3ad-cd714228ee82
} 
5. Race, P.: Evidencing Reflection: Putting the 'w' into reflection (ESCALATE Learning Exchange), http://www.escalate.ac.uk/exchange/Reflection (2002).

6. Francis, D.: Reflective Journal: A window to preservice teachers' practical knowledge. Teaching and Teacher Education. 11(3), 229-241(1995).

7. Langer, A.M.: Reflecting on Practice: Using learning journals in higher and continuing education. Teaching in Higher Education 7(3) 337-351 (2002).

8. Stephens, K., Winterbottom, M.: Using a Learning Log to Support Students' Learning in Biology Lessons; Journal of Biological Education, 44(2), 72-80 (2010).

9. Crook, C., Fisher, T., Harrop, H., Stokes, E.: New Modes of Technology-enhanced Learning: Developing successful practice. Becta, Coventry, UK, http://dera.ioe.ac.uk/1535/ (2010).

10. Schön, D. A.: Teaching Artistry through Reflection-in-action. In: Educating the Reflective Practitioner, pp. $22-$ 40. Jossey-Bass Publishers, San Francisco, CA (1987).

11. Higgins, S., Katsipataki, M., Kokotsaki, D., Coleman, R., Major, L.E., Coe, R.: The Sutton Trust-Education Endowment Foundation Teaching and Learning Toolkit. Education Endowment Foundation, London (2013).

12. Dewey, J.: How We Think, D. C. Heath, New York (1933).

13. Driscoll, J.: Practising Clinical Supervision: A Reflective Approach for Healthcare Professionals. 2nd ed. Bailliere Tindall Elsevier, Edinburgh (2007).

14. Ash, S.L., Clayton, P.H.: The Articulated Learning: An Approach to Guided Reflection and Assessment, Innovative Higher Education 29(2), 137-54 (2004).

15. Kember, D.: Determining the Level of Reflective Thinking from Students' Written Journals Using a Coding Scheme Based on the Work of Mezirow. International Journal of Lifelong Education 18(1), 18-30 (1999).

16. Lin, X., Hmelo, C., Kinzer, C.K., Secules, T.J.: Designing Technology to Support Reflection, Educational Technology Research and Development 47(3), 43-62 (1999).

17. Kori, K, Pedaste, M., Leijen, Ä., Mäeots, M.: Supporting reflection in technology-enhanced learning. Educational Research Review 11, 45-55 (2014).

18. Maclean, R., White, S.: Video Reflection and the Formation of Teacher Identity in a Team of Pre-service and Experienced Teachers. Reflective practice 8(1), 47-60 (2007).

19. Rich, P.J., Hannafin, M.: Video Annotation Tools Technologies to Scaffold, Structure, and Transform Teacher Reflection. Journal of Teacher Education 60 (1), 52-67 (2009).

20. Leijen, A., Lam, I., Wildschut, L., Simons, P.R-J., Admiraal, W.: Streaming Video to Enhance Students' Reflection in Dance Education, Computers \& Education 52, 169-176 (2009).

21. Augustsson, G.: Web 2.0, Pedagogical Support for Reflexive and Emotional Social Interaction Among Swedish Students, Internet and Higher Education 13, 197-205(2010).

22. Olofsson, A.D., Lindberg, J.O, Stödberg, U.: Shared Video Media and Blogging Online: Educational technologies for enhancing formative e-assessment? Campus-Wide Information Systems 28(1), 41-55 (2010).

23. Holland, L., Purnell, E.: Does the Use of Multimedia Technology Change or Improve First Year Information System Students' Level of Reflection? Reflective Practice 13(2), 281-294 (2012).

24. Hartnell-Young, E., Harrison, C., Crook, C., Pemberton, R., Joyes, G., Fisher, T., Davies, L.: Impact Study of eportfolios on Learning. Becta, Coventry, UK, http://dera.ioe.ac.uk/1469/1/becta 2007 eportfolios report.pdf (2007).

25. Luckin, R., Blight, B., Manches, A., Ainsworth, S., Crook, C., Noss, R.: Decoding Learning: The proof, promise and potential of digital learning. Nesta, London (2011).

26. Kozma, R.B. (ed).: Technology, Innovation and Educational Change: A global perspective.: International Society for Technology in Education, Eugene, OR (2003).

27. Boud, D., Walker, D.: Promoting Reflection in Professionals Courses: The challenge of context. Studies in Higher Education 23(2), 191-206 (1998).

28. Welch, M.: The ABCs of Reflection: A template for students and instructors to implement written reflection in service-learning. NSEE Quarterly 25, 22-25 (1999). 